\title{
EFFECT OF COLD STORAGE ON OPTICAL PROPERTIES OF SOME CITRUS FRUITS \\ El Shal, A.M.*
}

\begin{abstract}
$\underline{\text { ABSTRACT }}$
The objective of this research was to compare the optical properties of some citrus fruits (orange, mandarin and lemon) before and after cold storage over the visible and near-infrared wave region (400-1000 nm). AvaSpec-2048 Standard Fiber Optic Spectrometer was used to acquire spatially resolved diffuse reflectance images from the samples of orange, mandarin and lemon. Seven effective wavelengths (480, 535, 675, 720, 840, 880, $978 \mathrm{~nm})$ were selected to realize hyper-spectral tests. The obtained results show that for flesh and skin of fruits after cold storage, there was not any peak at $675 \mathrm{~nm}$ excluding orange skin, this attribute after cold storage fruits become over ripe that there was not chlorophyll content as before storage; cold storage had not any effect on chlorophyll content of orange skin. Results also show that there is a close correlation between the Plant Senescence Reflectance Index (PSRI) and fruit ripening.

Keywords: Spectrometer, Optical properties, Ripe, Chlorophyll, Cold storage
\end{abstract}

\section{INTRODUCTION}

Truit quality is defined as a measure of characters or
attributes that determine the suitability of the fruit to be
eaten as fresh or stored for reasonable period. So cold storage is very important for keeping quality of citrus fruit. The hyper-spectral imaging technique has been implemented in several applications such as defect detection or quality determination on apples, eggplants, pears, cucumber and tomatoes (Li et al., 2002;Liu et al., 2006) as well as physical, chemical and

*Lecturer, Agric. Eng. Dept., Fac. of Agric., Zagazig Univ., Egypt. 
mechanical properties estimation in various commodities (Lu, 2004; Nagata et al., 2005). In addition, a significant amount of research has been done in the area of spectroscopy and hyperspectral imaging applied especially to fruit analysis. The successful attempts to evaluate internal properties nondestructively were accomplished using spectral technology for prediction sugar content (Bellon et al., 1993), soluble solids (Park et al., 2003), firmness and acidity (Peirs et al.,2002), moisture content (Katayama et al.,1996), and so many other applications. The absorption coefficient at a given wavelength $\left(\mu_{\mathrm{a}}\right)$ can be interpreted as the linear combination of the extinction coefficients of main fruit components like water, chlorophyll, carotenes, sugars, etc. weighted by their average concentration. In a previous work aimed at quantifying the percentage volume of water and the chlorophyll- $a$ content in the bulk of the intact fruit, it was shown that chlorophyll is the dominant contributor to $\mu_{\mathrm{a}}$ at $670 \mathrm{~nm}$ (Cubeddu et al., 2001). Considering that in peaches and nectarines the chlorophyll content decreases with maturity, the hypothesis was made that the absorption coefficient $\mu_{\mathrm{a}}$ at $670 \mathrm{~nm}$ (near the chlorophyll peak) could be an index for identifying fruit maturity at harvest. The absorption coefficient $\mu_{\mathrm{a}}$ at $720 \mathrm{~nm}$ was significantly higher in brown heart pear tissue than that in sound tissue and the scattering coefficient $10 \mathrm{~s}$ at $720 \mathrm{~nm}$ was influenced by translucency of water-soaked tissue, as in over-ripe fruits and bruised regions (Zerbini et al., 2005). The samples containing higher moisture content had lower reflectivity across their spectra. In case of unripe fruit, the reflectance curve had three broadband absorption regions around 500,680, and $960 \mathrm{~nm}$ in addition to small absorption region at $840 \mathrm{~nm}$. The regions around 500 and 680 represent anthocyanin and chlorophyll pigments which represent the color characteristics in the fruit (Seeram et al., 2006). The absorption regions in the NIR at 840 and $960 \mathrm{~nm}$ represent sugars and water absorption bands. The reflectance from both ripe and overripe fruits was consistently lower than that from the unripe one over the entire spectral region. The chlorophyll 
absorption band at $680 \mathrm{~nm}$ was absent in case of ripe and overripe fruits due to the degradation of chlorophyll in these fruits. Meanwhile, the relative reflectance at anthocyanin and sugar absorbency bands (at 500 and $840 \mathrm{~nm}$, respectively) were much lower than those in unripe ones, meaning that the anthocyanin and sugars in the ripe and overripe fruits are much higher. Absorption due to carotene in the fruit tissue, has an absorption peak at 480 nm (Merzlyak et al., 2003). Large differences in the absorption spectra were observed for the tomatoes of three ripeness stages (green, pink, and red), and their ripeness was correctly classified using the ratio of the absorption coefficient at $675 \mathrm{~nm}$ (for chlorophyll) to that at $535 \mathrm{~nm}$ (for anthocyanin) (Qin and Lu, 2008). Considering that in orange, mandarin and lemon the chlorophyll content decreases with maturity, the hypothesis was made that the absorption coefficient $\mu_{\mathrm{a}}$ at $675 \mathrm{~nm}$ (near the chlorophyll peak) could be an index for identifying fruit maturity at harvest. The presence of water in the fruit caused a raise at the characteristic absorption bands that appear as localized minima. The samples containing higher moisture contents had lower reflectivity across their spectra. The absorption valleys around 500 and 680 represent carotenes and chlorophyll pigments which represent the color characteristics in the fruit (Abbott et al, 1997). The absorption valleys in the NIR at 840 and $960 \mathrm{~nm}$ represent sugar and water absorption bands. On the other hand, the reflectance from bruised surface, even from the recent ones, was consistently lower than that from the normal tissue over the entire spectral region (El Masry et al. 2008). The difference in reflectance between the bruised and un bruised tissue was the greatest in the NIR region, while it decreased dominantly in the visible region, and the spectral images had higher levels of noise with low reflectance especially in case of red and reddish background colors. This wavelength was found to be useful for predicting the firmness of apples (Moons et al., 1997) and the SSC of melons (Sugiyama, 1999). Wavelengths at 880and 905 $\mathrm{nm}$ were used for predicting the SSC of fruits (Moons et al., 
1997). Lu and Peng (2006) reported that the water absorption band was found to be at $950 \mathrm{~nm}$ using hyper-spectral imaging technique for peach fruits. It was found that the absorption coefficient at $670 \mathrm{~nm}\left(\mu_{\mathrm{a}} 670\right)$, the absorption peak of chlorophylla is linked to fruit biological age, and decreases as fruit ripen (Tijskens et al., 2006). In nectarines the conversion of $\mu_{\mathrm{a}} 670$ to a biological shift factor was successfully used to predict fruit softening rate during shelf life (Tijskens et al., 2007), allowing the selection of fruit for different market destinations (Eccher Zerbini et al.,2009). The absorption curve pattern for oranges is very similar to that of other fruit, such as the mandarin, mango, apple, cherry, peach and kiwifruit (Lu et al., 2000). So the main objective of the present study was to compare the optical properties of some citrus fruits (orange, mandarin and lemon) before and after cold storage over the visible and near infrared wave region (400-1000nm).

\section{MATERIALS AND METHODS}

In the present study, the optical properties of some citrus fruits were compared before and after cold storage .The practical experiments were carried out from $13^{\text {th }}$ march to $4^{\text {th }}$ of April 2012 at Debrecen University, Centre for Agricultural Sciences and Engineering, Faculty of Agricultural and Food Sciences and Environmental Management, Institute of Water and Environmental Management, Hungary.

\section{Materials:}

\section{The used citrus fruits:}

The following citrus fruits were used in the present study with the following specifications:

- Orange: $r$ r $3 \mathrm{~cm}^{3}$ volume, $95 \%$ percentage of sphericity and $228 \mathrm{~g}$ mass. 
- Mandarin: $162 \mathrm{~cm}^{3}$ volume, $84 \%$ percentage of sphericity and $140 \mathrm{~g}$ mass.

- Lemon: $110 \mathrm{~cm}^{3}$ volume, $74 \%$ percentage of sphericity and $100 \mathrm{~g}$ mass.

\section{The Spectrometer system:}

A laboratory AvaSpec-2048 Standard Fiber Optic Spectrometer system was constructed as shown in (Fig. 1).

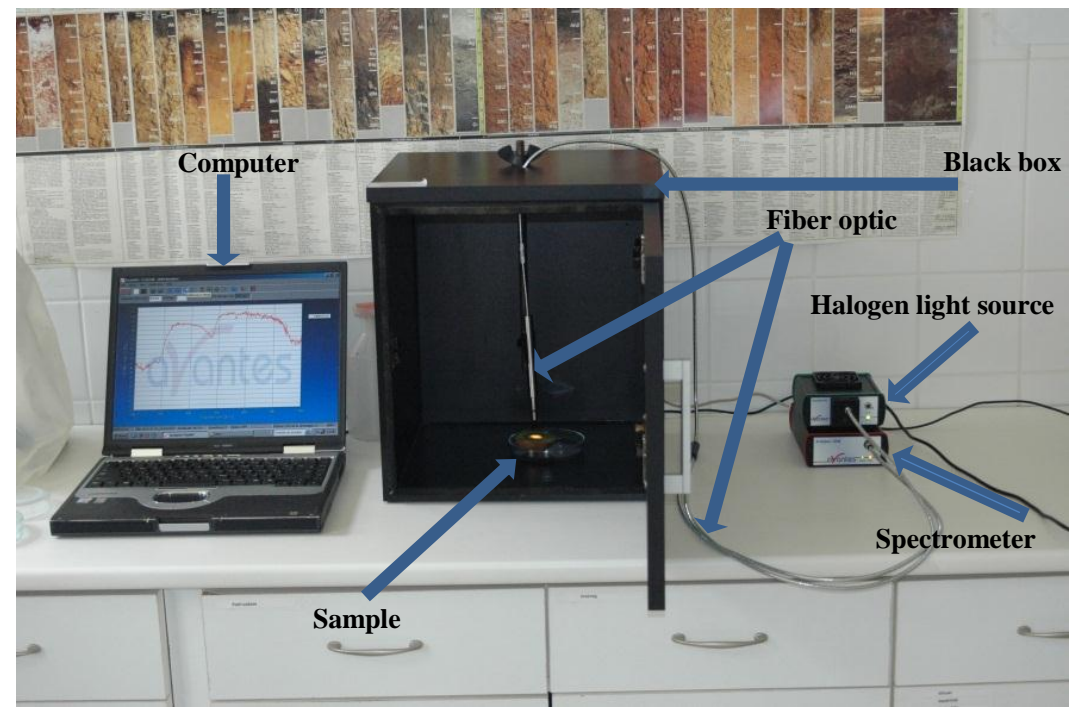

Fig. 1: AvaSpec-2048 Standard Fiber Optic Spectrometer system construction in operation.

The reflectance spectra were measured by AvaSpec 2048 Fiber Optic Spectrometer within 400-1000 nm interval. The AvaSpec 2048 system consists of a spectrometer (detector) and connected by an $8 \mu \mathrm{m}$ core diameter fiber optic standard AvaLight-HAL halogen light source. The light source has about $1 \mu \mathrm{Watt}$ light energy input to result the permanent light intensity in the whole measure range. The accurate measurement was provided by a special spectral sampling black box since the samples were isolated from the variable external light. 
Before the spectral measurement begin, the AvaSpec 2048 Spectrometer had to be calibrated by white and black references. The special type of reference unit is WS-2 reference tiles, was made out of white diffuse PTFE (polytetrafluoroethylene) based material, meeting the highest demands with regard to high grade diffuse reflectance. In case of calibration the distance of the reflection probe and reference tiles, these samples were three $\mathrm{cm}$.

The spectral data in the AvaSoft USB2 were processed, which is the own software of AvaSpec 2048 Spectrometer and Microsoft Office Excel ${ }^{\mathrm{TM}}$. Some parameters could be investigated based on spectral curves in the visible (VIS) and near infrared (NIR) ranges.

\section{Methods:}

\section{Fruit samples before and after cold storage:}

Three fresh healthy citrus fruits without symptoms of damage were obtained to investigate the spectral properties of fruits before and after cold storage. First measurement done immediately before storage in refrigerator about three weeks under about $3^{\circ} \mathrm{C}$., these test fruits were placed at room temperature around $\left(22 \pm 1^{\circ}\right.$ C) for around one day before second measurement. The measurement was performed on each sample in a Petri dish after cutting it to slices thickness about $1.5 \mathrm{~cm}$ for every slice as shown in (Fig 2).

\section{Experimental procedure:}

Seven effective wavelengths in the short-wave near infrared region $(480,535,675,720,840,880,978 \mathrm{~nm})$ were selected to realize multispectral imaging tests. Absorption coefficient ( $\mu$ a) at $480 \mathrm{~nm}$ (for carotene), at $535 \mathrm{~nm}$ (for anthocyanin), at $675 \mathrm{~nm}$ (for chlorophyll), at $720 \mathrm{~nm}$ (for bruised regions), at $840 \mathrm{~nm}$ (for sugar), at $880 \mathrm{~nm}$ (for starch), at $978 \mathrm{~nm}$ (for water content), technique provides a convenient and efficient means for measuring the optical properties of fruits. 


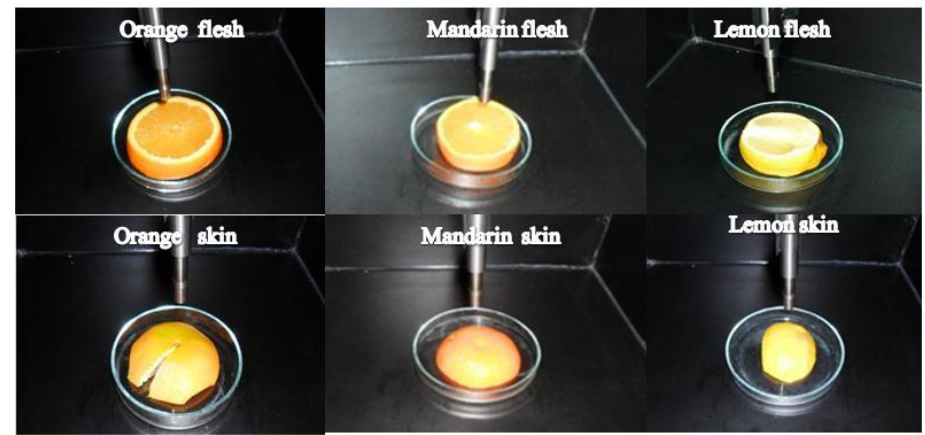

Fig. 2: Slices of orange, mandarin and lemon under measurement operation.

\section{Measurements:}

\section{Absorption coefficient:}

Absorption coefficients $\left(\mu_{\mathrm{a}}\right)$ of all fruits were collected in a range of (400-1000 nm) with AvaSpec-2048 Standard Fiber Optic Spectrometer, Spectral data were interfaced to a personal computer for further processing. The height between bottom end of sensor and the samples were about $3 \mathrm{~cm}$ and radiation diameter on slices was about $2.3 \mathrm{~cm}$. All of the measurements were averaged from the data from three replicates.

\section{Plant Senescence Reflectance Index (PSRI):}

In order to numerically observe the effect of cold storage on citrus fruits, Plant Senescence Reflectance Index values were created from the reflectance values at the studied wavelengths using the following equation (Merzlyak et al., 1999)

$$
P S R I=\frac{\rho_{678}-\rho_{500}}{\rho_{750}}
$$




\section{RESULTS AND DISCUSSIONS}

\section{Spectral properties of orange, mandarin and lemon fleshes before and after cold storage}

Fig. 3 shows that there is high decreasing $\left(\mu_{\mathrm{a}}\right)$ in lemon flesh lines than other fruits range 400 to $535 \mathrm{~nm}$. This mean that anthocyanins and carotenes were at low amounts, lemon flesh not reach final ripe stage enough as shown in Fig. 3 the $\left(\mu_{\mathrm{a}}\right)$ of the three fruits orange flesh, mandarin flesh and lemon flesh before cold storage all peaked at $675 \mathrm{~nm}$, which was attributed to chlorophyll content in the fruit tissue. The orange had smooth curve pattern $\left(\mu_{\mathrm{a}}\right)$, had small peak and other fruits had clear peaks at $675 \mathrm{~nm}$. This result attribute to that orange had reached ripe stage and lower chlorophyll content in the measurement than mandarin and lemon. About other effective wavelengths there are no observations excluding at lemon that had low $\left(\mu_{\mathrm{a}}\right)$ at $978 \mathrm{~nm}$ than other fruits because of containing less water in flesh than orange and mandarin.

After cold storage curve pattern were smooth, there was not any peak at $675 \mathrm{~nm}$, this attribute after cold storage fruits become over ripe that there is not chlorophyll content as before storage. At 978 $\mathrm{nm}$ the curve pattern is higher than fruits before cold storage. This means that fruits had more water in tissue.

\section{Spectral properties of orange, mandarin and lemon skins before and after cold storage}

Fig . 4 shows that orange skin before cold storage have deep clear peak at $675 \mathrm{~nm}$, which was attributed to high amount of chlorophyll in the skin and did not observe this in other skin of fruits, this mean that skin of orange have more chlorophyll content than other skin of fruits. Observed that skin of orange at $978 \mathrm{~nm}$ had lowest $\left(\mu_{\mathrm{a}}\right)$ then mandarin skin and lemon skin respectively. This mean orange skin had less water than mandarin skin and lemon skin respectively. About other effective wavelengths there are no observations.

After cold storage all curve pattern were smooth, there is not any peak at $675 \mathrm{~nm}$, except orange skin that had deep clear peak at 

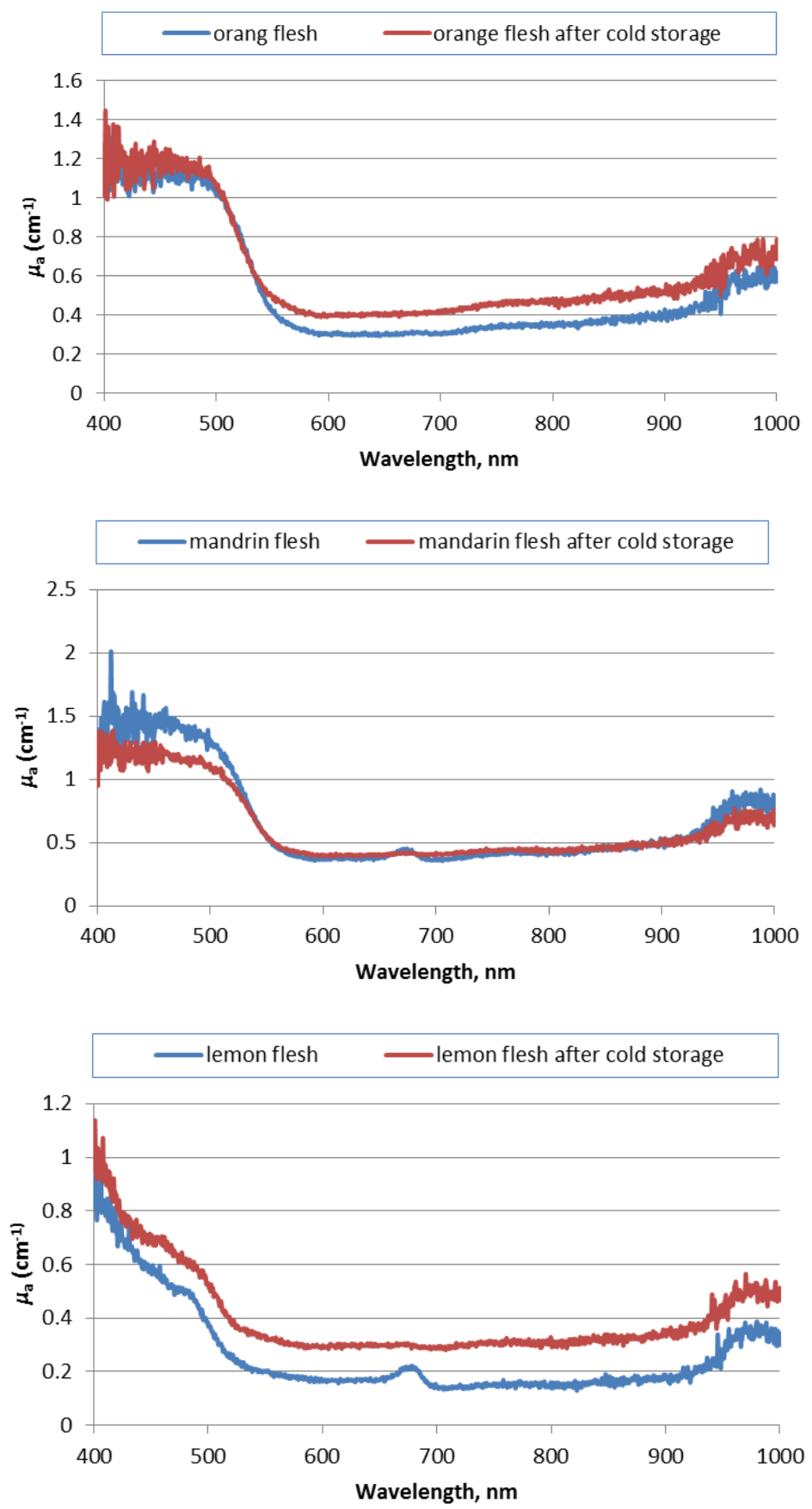

Fig. 3: Absorption coefficient $\left(\mu_{\mathrm{a}}\right)$ of orange, mandarin and lemon fleshes before and after cold storage. 

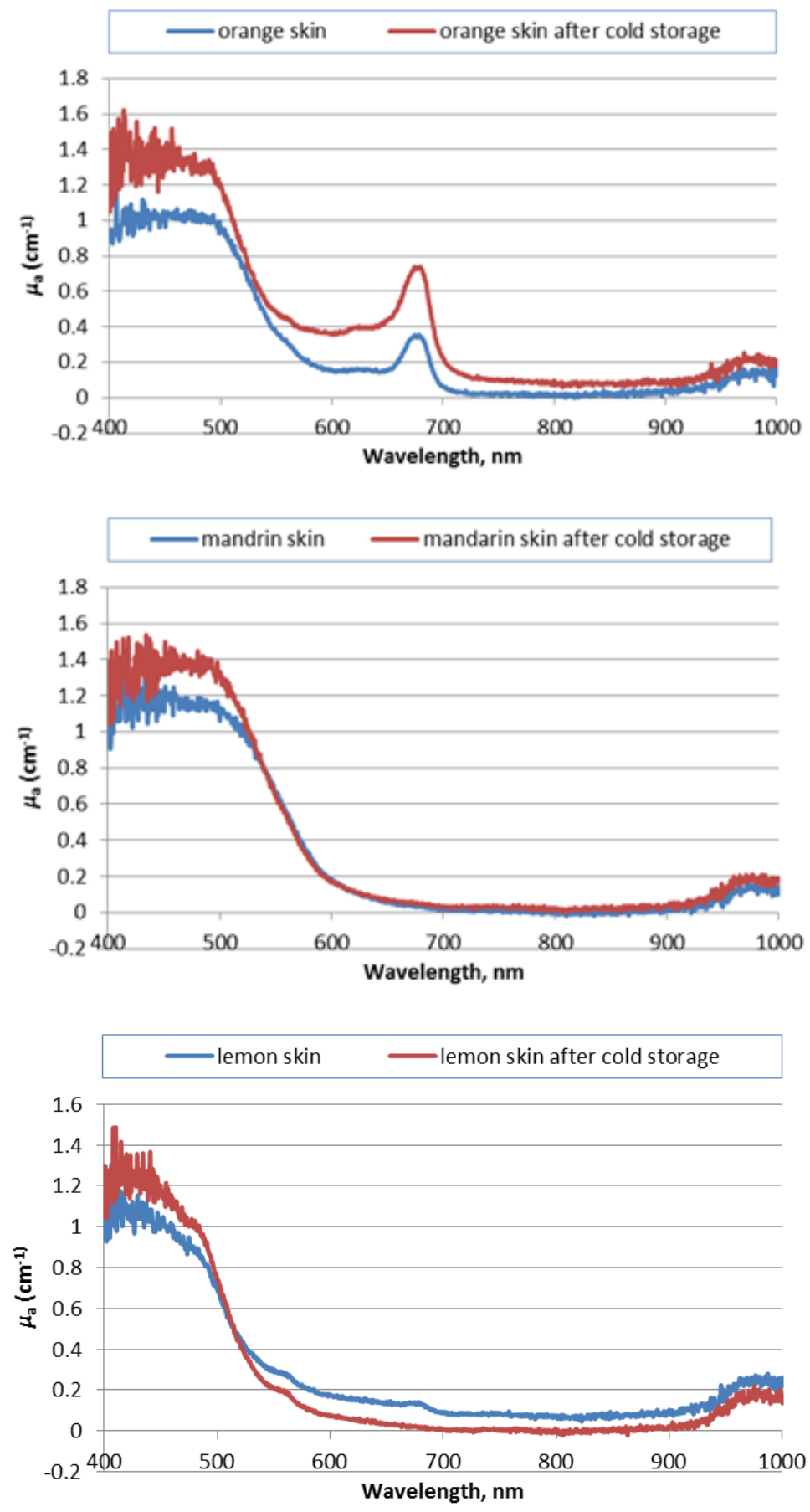

Fig. 4: Absorption coefficient $\left(\mu_{\mathrm{a}}\right)$ of orange, mandarin and lemon skins before and after cold storage. 
$675 \mathrm{~nm}$, which was attributed to a high amount of chlorophyll content in the skin after cold storage this mean that cold storage had not any effect on chlorophyll content of orange skin.

\section{Plant senescing Reflectance Index}

Fig. 5 shows the plant senescing reflectance index values for the studied citrus fruits before and after cold storage. Results in Fig .5 shows that there is a close correlation between the plant senescing reflectance index and fruit ripening.

The same results also show that these indices were higher in the case of cold storage comparing with before cold storage due to the over ripening after cold storage.

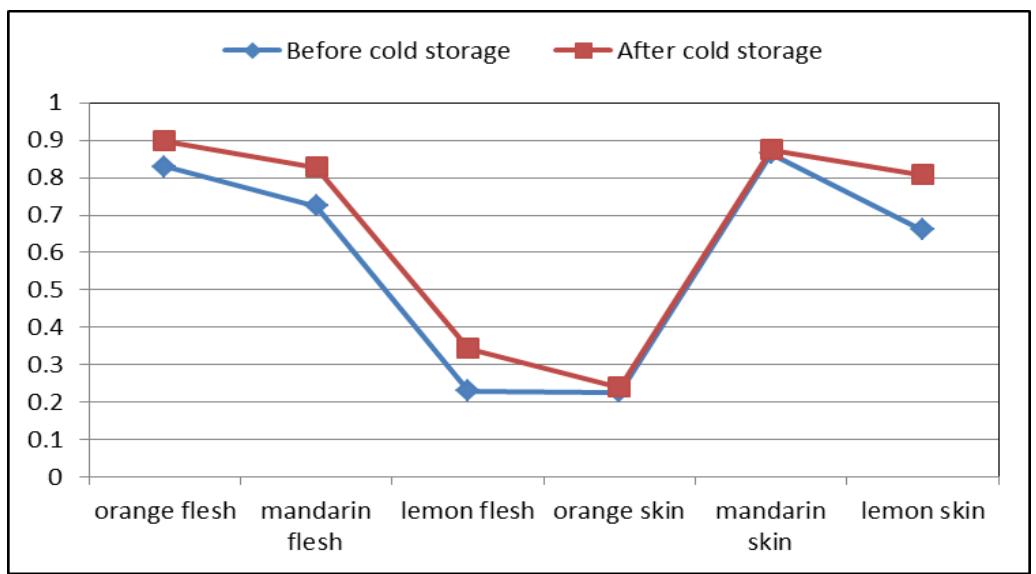

Fig .5: Plant senescing reflectance index before and after cold storage.

\section{CONCLUSION}

The developed hyperspectral methods provide opportunity to support a nondestructive technique for assessing the postharvest quality of citrus fruits. After cold storage curve patterns were smooth, there was not any peak at $675 \mathrm{~nm}$ excluding orange skin. This attribute after cold storage fruits become over ripe that there was not chlorophyll content as before storage, cold storage had not any effect on chlorophyll of orange skin. 
PROCESS ENGINEERING

\section{REFERENCES}

Abbott, J. A., R. Lu, B. L. Upchurch and R.L. Stroshine (1997). Technologies for non-destructive quality evaluation of fruits and vegetables. In Horticultural reviews. Technologies for nondestructive quality evaluation of fruits and vegetables (Vol. 20, pp. 1-120). John Wiley, Sons, Inc. ISBN 0-471-18906-5.

Bellon, V., J. L. Vigneau and M. Leclercq (1993). Feasibility and performance of a new, multiplexed, fast and low-cost fiber-optic NIR spectrometer for the online measurement of sugars in fruits. Applied Spectroscopy 47 (7):10791083.

Cubeddu, R., C. D'Andrea, A. Pifferi, P. Taroni, A. Torricelli, G. Valentini, C. Dover, D.Johnson, M. Ruiz-Altisent and C. Valero (2001). Nondestructive quantification of chemical and physical properties of fruits by time-resolved reflectance spectroscopy in the wavelength range 650-1000 nm. Applied Optics 40:538543.

Eccher Zerbini, P., M. Vanoli, A. Rizzolo, S. Jacob, A. Torricelli, L. Spinelli and R.E. Schouten (2009). Time-resolved reflectance spectroscopy as a management tool in the fruit supply chain: an export trial with nectarines. Biosyst. Eng. 102:360-363.

El Masry, G., N. Wang, C. Vigneault, J. Qiao and A. El Sayed (2008). Early detection of apple bruises on different background colors using hyper-spectral 
imaging. LWT - Food Science and Technology 41 (2):337-345.

Katayama, K., K. Komaki and S. Tamiya,(1996). Prediction of starch, moisture, and sugar in sweet potato by near infrared transmittance. HortScience, 31 (6):1003-1006.

Li, Q., M. Wang and W. Gu (2002). Computer vision based system for apple surface defect detection. Computers and Electronics in Agriculture 36 (2):215-223.

Liu, Y., Y. R. Chen, C. Y.Wang, D. E. Chan and M. S. Kim (2006). Development of hyper-spectral imaging technique for the detection of chilling injury in cucumbers; spectral and image analysis. Applied Engineering in Agriculture 22 (1):101-111.

Lu, R., D.E. Guyer and R.M. Beaudry (2000). Determination of firmness and sugar content of apple using NIR diffuse reflectance. J. Texture Stud. 31:615-630.

Lu, R. (2004). Multispectral imaging for predicting firmness and soluble solids content of apple fruit. Postharvest Biology and Technology 31 (1):147-157.

Lu, R. and Y. Peng (2006). Hyper-spectral Imaging for assessing peach fruit firmness. Biosystems Engineering 93 (2):161171.

Merzlyak, M.N., A.A. Gitelson, O.B. Chivkunova and V.Y. Rakitin (1999). Non- destructive optical detection of pigment changes during leaf senescence and fruit ripening. Physiologia Plantarum 106:135-141. 
Merzlyak, M.N., A.E. Solovchenko and A.A. Gitelson (2003). Reflectance spectral features and non-destructive estimation of chlorophyll, carotene and anthocyanin content in apple fruit. Postharvest Biol. Technol. 27:197211.

Moons, E., P. Dardenne, A. Dubois and M.Sindic (1997). Nondestructive visible and NIR spectroscopy measurement for the determination of apple internal quality. Acta Hort. 517:441-448.

Nagata, M., J. G. Tallada, T. Kobayashi and H. Toyoda (2005). NIR hyper-spectral imaging for measurement of internal quality in strawberries. ASAE meeting, Tampa, Florida, ASAE Paper No. 053131.

Park, B., J. A. Abbott, K. J. Lee, C. H. Choi and K. H. Choi (2003). Near-infrared diffuse reflectance for quantitative and qualitative measurement of soluble solids and firmness of Delicious and Gala apples. Transactions of the ASAE 46 (6):1721-1731.

Peirs, A., N. Scheerlinck, K. Touchant and B. M. Nicolai (2002). Comparison of Fourier transform and dispersive near-infrared reflectance spectroscopy for apple quality measurements. Biosystems Engineering 81 (3):305-311.

Qin, J. and R. Lu (2008). Measurement of the optical properties of fruits and vegetables using spatially resolved hyperspectral diffuse reflectance imaging technique. Postharvest Biology and Technology 49:355-365. 
PROCESS ENGINEERING

Seeram, N. P., R. Lee, H. S. Scheuller and D. Heber (2006). Identification of phenolic compounds in strawberries by liquid chromatography electrospray ionization mass spectroscopy. Food Chemistry 97 (1):1-11.

Sugiyama, J.(1999). Visualization of sugar content in the flesh of a melon by near-infrared imaging. J. Agric. Food Chem. $47: 2715-2718$.

Tijskens, L.M.M., P. Eccher Zerbini, M. Vanoli, S. Jacob and M. Grassi (2006). Effects of maturity on chlorophyllrelated absorption in nectarines, measured by nondestructive time-resolved reflectance spectroscopy. Int. J. Postharvest Technol. Innov. 1:178-188.

Tijskens, L.M.M., P. Eccher Zerbini, R.E. Schouten, M. Vanoli, S.Jacob, M. Grassi, R.Cubeddu, L. Spinelli and A.Torricelli (2007). Assessing harvest maturity in nectarines. Postharvest Biol. Technol. 43:204-213.

Zerbini, P. E., M. Grassi, R. Cubeddu, A. Pifferi and A. Torricelli (2005). Nondestructive detection of brown heart in pears by time resolved reflectance spectroscopy. Postharvest Biology and Technology 25:87-97. 


\section{الملخص العربي}

تأثير التخزين البارد على الخصائص البصرية لبعض الحمضيات

أحمد محمد الثال"

يهذف هذا البحث لدراسة تأثير التخزين البارد على الخصائص البصرية لبعض تلإئ

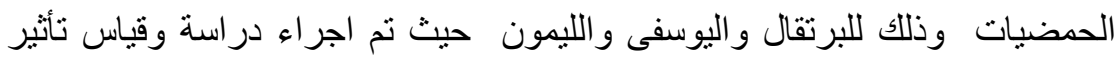

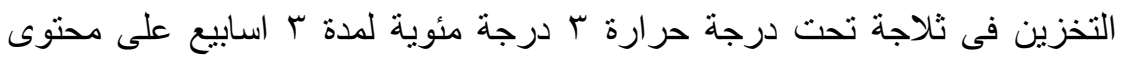

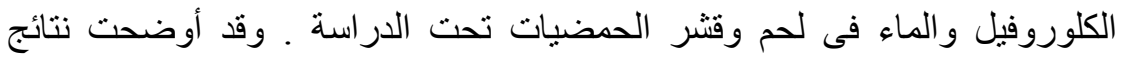

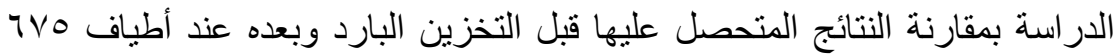

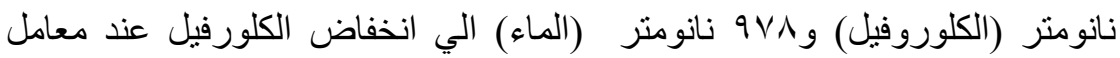

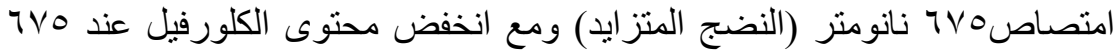
نانومتر يحدث زيادة محتوى الماء عند

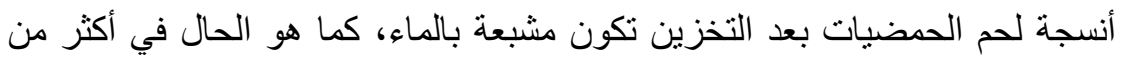

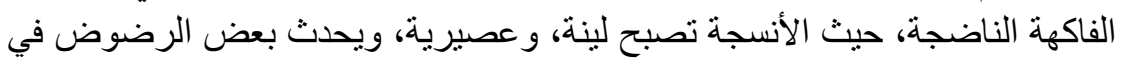

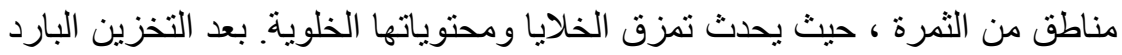

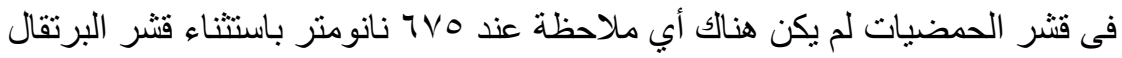

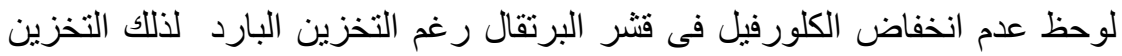

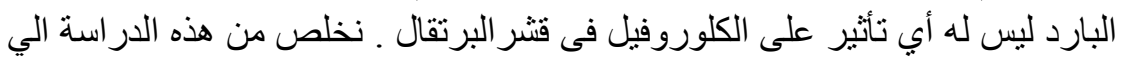

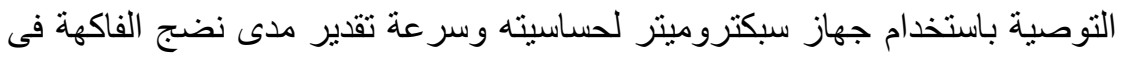

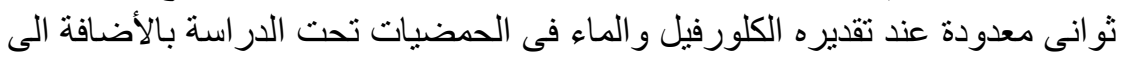

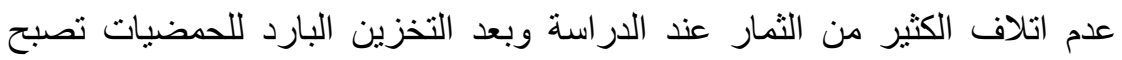
ناضجة أكثر حيث أنه يقل محتوى الكلوروفيل عما كان عليه قبل التخزين حيث يزيد التيد

محتوى الماء بالأنسجة.

* مدرس الهندسة الزراعية _ كلية الزراعة - جامعة الزقازيق - مصر. 